FEATURE

John C Hughes

Office for National Statistics

\section{SIC 2007: implementation in ONS}

2007 - a series of consultations started in 2002 and carried out in conjunction with the major revision of the European Union's industrial classification system, NACE (Nomenclature Générale des Activités Économiques dans les Communautés Européennes).

These revisions are motivated by the need to adapt the classifications to changes in the world economy. While milling and ploughing were predominant activities in the economy in 1086, retailing and financial services might be considered more significant in 2008, and the range of today's economic activity is more diverse. In essence, the introduction of SIC 2007 reflects the growing importance of service activities in the economy over the last 15 years, and in particular the developments in information and communication technologies (ICT).

In this respect, SIC 2007 also presents many challenges not previously encountered, taking place in the more technological environments in which people now live and work. Whereas the previous major revision in the early 1990s took place in predominantly paper-based offices, the new classification requires significant changes to the computerised systems which support the statistical process.

In a broader context, there are significantly greater international requirements for data classified by industry than in 1992. There is also a greater demand for statistics relating to the services sector than at any time previously and, in general, 
more analytical work using statistics for comparability. In many ways, therefore, the introduction of SIC 2007 represents the biggest change to industrial classifications since their formal introduction in 1948.

\section{The international context}

The UK SIC is a hierarchical five-digit classification system which is required by EU legislation to be identical to NACE down to, and including, the four-digit Class level. The five-digit level has been added, for UK purposes only, to form Subclasses in cases where it was considered necessary or potentially helpful. In turn, both SIC and NACE are based on the United Nations International Standard Industrial Classification (ISIC), and are identical at the two-digit level. Beyond this there are some differences in terms of combinations and numbering. SIC 2007 is based on NACE Revision $2,{ }^{2}$ which in turn is based on ISIC Revision 4.

\section{The new classification}

SIC 2007 comprises 21 Sections (denoted by a single letter from A to U), 88 Divisions (denoted by two digits), 272 Groups (three digits), 615 Classes (four digits) and 191 Subclasses (five digits). A key difference in the structure of SIC 2007 is the removal of subsections, of which there were 16 for SIC 2003 relating mainly to 'Mining and quarrying' and to 'Manufacturing.'

SIC 2007 includes a number of new sections giving more service sector detail:

- Section J - 'Information and communication': this is a major new section, consisting of 26 four-digit level classes and pulling in activity from many parts of NACE. It will bring together: publishing; motion picture and sound recording industries; broadcasting (radio and TV industries); telecommunications; internet activities; and other news services

- Section L - 'Real estate activities': currently part of SIC 2003 Section $\mathrm{K}$, 'Real estate, renting and business activities'. Development and selling

Table 1 of real estate moves from the service sector to 'Construction'

- Section M - 'Professional, scientific and technical services': currently part of SIC 2003 Section K which consists of only 17 four-digit level classes, this new section will contain 19 four-digit classes

- Section N - 'Administrative and support services': currently part of SIC 2003 Section K, this new section contains 33 four-digit classes and will include: employment services; call centres; travel arrangements and reservation services; and investigation and security services

- Section R - 'Arts, entertainment and recreation': currently part of SIC 2003 Section O, 'Other community, social and personal service activities'. There are 15 four-digit level classes

The introduction and guidance notes to the new classification, and the SIC 2007 index, were published on the National Statistics website $^{3}$ on 14 December 2007. The Office for National Statistics (ONS) Business Registers Unit has produced a correlation between SIC 2003 and SIC 2007 - this can also be accessed via the ONS website. ONS is currently working on a correspondence table based on 'counts' of businesses, and similar tables based on other variables, for example, employment and turnover. Beyond this, it should be possible to produce correspondence tables based on survey data, initially using the results from the 2008 Annual Business Inquiry (ABI).

\section{Key changes between SIC 2003 and SIC 2007}

Table 1 presents a broad breakdown of the change in structure between SIC 2003 and SIC 2007. A key difference is the removal of subsections for SIC 2007 but, in general, the table demonstrates the expansion in the number of categories under the new classification.

Most of the new categories relate to service activities: for example, at twodigit level, the number of divisions for manufacturing remains roughly the same, whereas there are almost three times as many divisions for 'Real estate, professional and administrative' service activities under SIC 2007 as under SIC 2003.

The precise impact of the change in structure on data outputs will become more apparent once more detailed analysis has been carried out, but it is clear that the move to SIC 2007 will require careful management in order to avoid distorting statistical series. Communication of these issues to data users will also be fundamental to ONS plans for implementing this change.

As mentioned earlier, the new classification reflects the economic world in which people now live when compared with the time of the last major revision in the early 1990s. Some of the significant changes are detailed below.

- Business activities - this broad heading was part of section $\mathrm{K}$, 'Real estate, renting and business activities', under the previous classification, but now moves to several different areas including Section M, 'Professional, scientific and technical activities'; Section N, 'Administration and support services'; Section S, 'Other service activities'; and Section J, 'Information and communication'. This major new section covers many activities that are now taken for granted but which were barely conceived of in the early 1990s. Even though the earliest mobile phones and portable music systems date back to early 1970s, most people would have gained access to these and other technological items some time in the last ten to 15 years. The explosion of ICT activities is well reflected in the new Section J, which includes publishing, film and broadcasting activities and news agencies, in addition to telecommunication and computerrelated activities

- Retail sale of automotive fuel - until now, this activity has been considered part of the motor trade, which to many might conjure up an image of a bygone age when filling up with a tank of petrol meant stopping at a roadside garage and being attended to by a mechanic who might check oil levels and tyre pressures as part of the service. In today's motoring world, most people fill up at an out-of-town supermarket complex where, thanks to automation, they can pay at the pump without even engaging with a member of staff. The sale of fuel is now considered very much a retail activity - and this is reflected by its 
new classification to Group 47.3 (Retail sale of automotive fuel in specialised stores). For ONS, this presents certain challenges, particularly given that the Retail Sales Index currently excludes petrol sales

- Recycling - in the early 1990s, most would have considered their waste management activity to involve no more than 'putting the bins out' on the night before collection. In the environmentally-conscious 21 st century, recycling is part of people's everyday lives, with a variety of receptacles provided by local authorities to assist with waste management. This significant culture shift sees recycling move from Section D, 'Manufacturing, in SIC 2003 to Section E, 'Water supply, sewerage, waste management and remediation activities', under SIC 2007

- Manufacturing - recycling is one of several key activities which are no longer considered part of manufacturing (another significant activity is publishing, which moves to Section J). In these cases, new sectors have been created for their classification under SIC 2007 and this has been achieved partly by moving activity to them from the current sectors. However, manufacturing is significantly smaller as a proportion of economic activity under SIC 2007, which reflects the move towards more services-based economies over the past 20 years

In essence, SIC 2007 paints a picture of economic life in the early 21 st century, in the same way that the Doomsday Book reflected life in the 11th century. The changes made since SIC 2003 and SIC
92 also underline the scale and pace of change in the modern world, the inevitable continuation of which will require a further revision in the not too distant future.

\section{ONS plans for the transition}

The outline implementation plan for SIC 2007 across all ONS outputs is:

- for reference year 2008, the ABI (parts 1 and 2) will be based on SIC 2007

- PRODCOM (Products of the European Community) will also be based on SIC 2007 from reference year 2008

- other annual outputs will be based on SIC 2007 from reference year 2009, unless otherwise determined by regulation or other requirements

- short-term surveys (those carried out on a quarterly and monthly basis) and prices surveys will be based on SIC 2007 from the first reference period in 2010, unless otherwise determined by regulation or other requirements

- National Accounts will move to SIC 2007 in September 2011

Within the scope of this implementation strategy, the following timetable is emerging, as detailed in Table 2.

In terms of data outputs, plans are being developed: for example, ABI1 will publish data on the new basis for reference year 2008, and will make some information available on the old basis; ABI2 will have results on both bases for reference year 2007 and will be published based on SIC 2007 only from 2008; PRODCOM plans to publish on one basis only (SIC 2003 for reference year 2007 and SIC 2007 from 2008).

The short-term surveys will produce

Table 2

\section{Timetable for the implementation of SIC 2007 in ONS}

\begin{tabular}{ll}
\hline Date & Event \\
\hline $\begin{array}{l}\text { January 2008 } \\
\text { September 2008 }\end{array}$ & All units on the business register dual coded to SIC 2003 and SIC 2007 \\
& ABI (parts 1 and 2) and PRODCOM surveys (reference year 2008) will be selected on an SIC 2007 basis \\
for the first time \\
March 2009 & Monthly survey statistics will be converted from SIC 2003 to SIC 2007 to meet European obligations \\
May 2009 & Quarterly survey statistics will be converted from SIC 2003 to SIC 2007 to meet European obligations \\
During 2009 & Household surveys will implement SIC 2007 (including the Labour Force Survey from \\
& quarter 1 - published in May 2009) \\
During 2009 & Other annual business surveys will implement SIC 2007 for reference year 2009 \\
October 2009 & PRODCOM 2008 reference year publication based on SIC 2007 \\
December 2009 & ABI2 2007 reference year data converted to SIC 2007 to meet European obligations \\
January 2010 & Monthly surveys selected on SIC 2007 basis for the first time \\
March 2010 & Quarterly surveys selected on SIC 2007 basis for the first time \\
During 2010 & Short-term survey statistics converted from SIC 2007 to SIC 2003 for use by National Accounts \\
During 2010 & Prices surveys will be based on SIC 2007 for the first time \\
June 2010 & ABI2 2008 reference year data published on SIC 2007 for the first time \\
July 2010 & ABI2 2008 reference year regional data published on SIC 2007 for the first time \\
September 2011 & National Accounts (Blue Book 2010) based on SIC 2007 for the first time \\
December 2011 & Regional Accounts based on SIC 2007 for the first time \\
\hline
\end{tabular}

back series on the new SIC, although final decisions on the length and detail of these series have yet to be made. Where ONS has time series in an index form, any significant discontinuities will be linked out of the series (for the Index of Production and the Index of Services, for example). The early work on these indicators will show if there are lower-level series which are subject to large changes. ONS will investigate the largest of any such discontinuities. For structural surveys such as ABI, it will not be practical to perform such a linking exercise but, in these cases, there will be two years of parallel running.

ONS is aware that the phased timetable presents challenges which will impact upon survey respondents, data suppliers and customers. ONS will continue to present details of the new classification, index and explanatory notes on the SIC page of the National Statistics website. Changes to specific surveys and outputs will be pre-announced at an appropriate time through the relevant media. Other articles publicising details of the transition to SIC 2007 will be released periodically at key points in the process.

Implementation of SIC 2007 for nonONS surveys is the responsibility of the relevant government department. However, where ONS manages such surveys on behalf of a department, plans made in consultation with the client department are already in hand. Most of these surveys make use of the Inter-Departmental Business Register as a sampling frame. The Department for Business, Enterprise \& Regulatory Reform is undertaking a wider role to coordinate implementation timetables for all non-ONS surveys.

\section{Conclusion}

All of this presents the statistical community with a massive challenge over the next three and a half years, by which time all National Accounts systems and outputs will also be based on SIC 2007. Communicating plans in terms of changes to surveys, outputs and publication will be central to the implementation. Further articles will be published in Economic \& Labour Market Review in order to expand on implementation for non-ONS surveys and to add further detail to the plans for National Accounts outputs such as the Index of Production, the Index of Services and the Retail Sales Index. 


\section{Notes}

1 The minor revision in 1997 was not accompanied by a visible change of title, so no reference is made to an $\operatorname{SIC}(97)$.

2 For further details see http://circa.europa.eu/irc/dsis/ nacecpacon/info/data/en/index.htm

3 For further details see www.statistics.gov.uk/statbase/product. asp?vlnk=14012

\section{CONTACT}

(艾 elmr@ons.gsi.gov.uk 